\title{
Differential Involvement of Parietal and Precentral Regions in Movement Preparation and Motor Intention
}

\author{
Daniel Thoenissen, ${ }^{1}$ Karl Zilles, ${ }^{1}$ and Ivan Toni ${ }^{1,2}$ \\ 1/nstitut für Medizin, Forschungszentrum Jülich, D-52425 Jülich, Germany, and 2F. C. Donders Centre for Cognitive \\ Neuroimaging, University of Nijmegen, NL-6500 HB Nijmegen, The Netherlands
}

Flexible goal-oriented behavior relies on spatial coordinate transformations and motor control mechanisms, but also on the capability to take advantage of contextual information for steering the sensorimotor machinery. Although accurate performance of a sensorimotor task requires parietal and frontal regions, their differential contribution and functional relationship with other associative regions remains obscure.

We have used event-related functional magnetic resonance imaging to measure human cerebral activity associated with motor cognitive processes in the context of delayed performance of an associative visuomotor task. Movement instruction (specified by visual cues) and motor performance (specified by an auditory cue) were separated by a variable delay period. By manipulating the predictive value of the instruction cue, we distinguished delay-related activity influenced by response probabilities (motor preparation and motor inhibition) from delay-related activity unaffected by the likelihood of providing a motor response (motor intention).
We found delay-related activity distributed across a cerebral network involving not only frontal circuitry, but also extrastriate and mediotemporal regions. Areas showing motor intentions and preparatory responses were spatially intermingled. Posterior parietal cortex deviated from this pattern, showing delayrelated activity regardless of movement probability, but no specific preparatory responses.

These results suggest that posterior parietal cortex and dorsal precentral cortex play different strategic roles in handling associative visuomotor problems. While parietal regions cover a range of potential responses defined by the task setting, precentral regions focus on a likely movement. Temporoprefrontal regions might incorporate contextual information in the visuomotor process by defining potential and probable responses on the basis of the task contingencies.

Key words: posterior parietal cortex; premotor cortex; temporal cortex; hippocampus; delay-related activity; visuomotor associations
Following Mishkin et al. (1983) and Goodale et al. (1991), it is widely accepted that the dorsal visual pathway is involved in the spatial guidance of primate behavior. However, the specific contributions of the posterior parietal cortex to visuomotor processes have been sharply debated. Single-unit recordings on the lateral bank of the macaque intraparietal sulcus have led some authors to argue that posterior parietal cortex integrates and selects sensory information to be conveyed toward frontal executive areas (Robinson et al., 1978; Gottlieb et al., 1998) while anticipating the consequences of a movement (Duhamel et al., 1992; Eskandar and Assad, 1999). An alternative view, gathered mainly from electrophysiological surveys on the dorsal and posterior aspects of the parietal lobe, has suggested for this region a "command function" (Mountcastle et al., 1975; Lynch, 1980), implying that motor plans rather than sensory stimuli are the crucial elements handled by the parietal cortex (Snyder, 2000).

Such debate has often been fought over the terrain of complex spatial coordinate transformations (Andersen et al., 1997; Burnod

\footnotetext{
Received March 11, 2002; revised June 11, 2002; accepted June 27, 2002.

I.T. was supported by the F. C. Donders Centre (Nijmegen) and the Hermann von Helmholtz Gemeinschaft. Author contributions are as follows: experimental design (I.T.), data collection (D.T., I.T.), data analysis (D.T., I.T.), and manuscript preparation (D.T., I.T., K.Z.). We thank M.-L. Grosse-Ruyken for expert assistance during scanning; F. Boers for help during the EMG measurements; and M. Niedeggen, G. Fernandez, R. E. Passingham, and two anonymous reviewers for invaluable comments.

Correspondence should be addressed to Dr. Ivan Toni, F. C. Donders Centre for Cognitive Neuroimaging, University of Nijmegen, P.O. Box 9101, NL-6500 HB Nijmegen, The Netherlands. E-mail: ivan.toni@fcdonders.kun.nl.

Copyright (C) 2002 Society for Neuroscience $0270-6474 / 02 / 229024-11 \$ 15.00 / 0$
}

et al., 1999; Colby and Goldberg, 1999). However, sensorimotor processes are not just intricate stimulus-response reflexes (Jeannerod, 1997). Flexible goal-oriented behavior makes use of expectations and contextual information through top-down processes that bias the responses of posterior regions (Frith, 2000; Passingham et al., 2000). Therefore, the contribution of parietofrontal circuits to visuomotor performance is best studied in the context of integrative activities occurring over distributed cerebral networks.

Here we aim at differentiating the contribution of posterior parietal cortex to associative visuomotor behavior in relation to a large-scale cerebral network. We have assessed the functional anatomy of motor cognitive processes by segregating delayrelated responses from sensory- and movement-related activities. Importantly, we have modulated behavioral correlates of motor preparation by manipulating the predictive value of an instruction cue (Low and Miller, 1999; Platt and Glimcher, 1999; Quintana and Fuster, 1999) while balancing sensory, attentional, and executive components of the task. This has allowed us to overcome the limitations intrinsic in disentangling different roles of delayrelated activity on purely temporal grounds. Our behavioral challenge evoked delay-related activity that was influenced by response probabilities (motor preparation and motor inhibition) as well as delay-related activity that was unaffected by the likelihood of providing a motor response (motor intention). Although intentional control of action can be conceptually dissociated from stimulus-triggered responses (Rossetti and Pisella, 2002), here we follow previous electrophysiological reports (Kalaska and Cram- 
mond, 1995; Snyder et al., 1997, 2000), labeling as "motor intention" those neural responses that are independent from action performance but still involved in specifying potential movements (Calton et al., 2002).

We found several brain regions in which motor intentions and preparatory responses were spatially intermingled. Posterior parietal cortex deviated from this pattern, showing delay-related activity regardless of movement probability but no preparatory activity as a function of response likelihood. These results reveal a crucial difference in the strategy adopted by parietal and frontal regions to solve sensorimotor problems. While parietal activity appears to cover a range of potential responses defined by the task settings, precentral activity appears to focus on a probable movement defined by the task contingencies.

\section{MATERIALS AND METHODS}

Experimental setup. We studied six right-handed [laterality ratio: 0.7-1 (Oldfield, 1971)] male volunteers (20-29 years of age) after obtaining informed consent and with approval of the ethics committee of the University Hospital of Heinrich Heine University (Düsseldorf). The subjects lay supine in the scanner. Head movements were minimized by an adjustable padded head holder. Visual stimuli were projected onto a screen above the subjects' heads. The visual stimuli (green and red shapes on a black background) subtended a visual angle of $\sim 20^{\circ}$. The acoustic stimuli ( 0.3 or $1.7 \mathrm{kHz}$ tones) were presented binaurally via magnetic resonance imaging (MRI)-compatible piezoelectric headphones, which also protected the subjects from the scanner noise. Motor responses were recorded via an MR-compatible keypad (Lumitouch), positioned on the right side of the subject's abdomen. Stimulus presentation and response collection were controlled by a PC and synchronized with the scanner through a second PC during the entire experiment.

On a separate occasion, four subjects underwent a further scanning session to assess skeletomotor and oculomotor activities during task performance. Bipolar surface EMGs were recorded $(1 \mathrm{kHz})$ from the flexor or extensor digitorum superficialis of the right forearm (bandpass filter 1-200 Hz, notch filter $50 \mathrm{~Hz}$ ). Eye position was recorded $(60 \mathrm{~Hz})$ in two dimensions with an infrared video-oculographic system (Applied Science Laboratories) (Gitelman et al., 2000). To collect meaningful EMG data, the MR gradients were turned off during the EMG measurements.

Task. The experiment consisted of three training sessions and eight scanning sessions. During the first training session (360 trials), the subjects learned by trial and error a visuomotor associative task with instructed delays (Toni et al., 1999, 2002a). In brief, one of four patterns (white shapes on black background) was presented for $300 \mathrm{msec}$. Two shapes instructed the subjects to flex the right index finger; the other two shapes instructed the flexion of the right middle finger. After a variable delay period $(0.1-1.0 \mathrm{sec}$ in steps of $0.1 \mathrm{sec})$, a tone was presented for 300 msec. The subjects were instructed to respond as quickly as possible after the trigger cue (reaction time cutoff $=600 \mathrm{msec}$ ). Feedback on accuracy of performance was provided across the three training sessions (a yellow tick for correct responses, a blue cross for wrong responses).

During the second training session (40 trials), the subjects learned by trial and error a Go-Nogo task with instructed delays. A colored circle (either green or red) was presented for $300 \mathrm{msec}$. A variable delay period followed $(1.2-2.0 \mathrm{sec}$, in steps of $0.2 \mathrm{sec})$. At the presentation of an auditory trigger cue (either 0.3 or $1.7 \mathrm{kHz}, 300 \mathrm{msec}$ ), the subjects were required to provide a response. The pitch of the trigger cues instructed the subjects either to flex the right index finger or to withhold the response. The color of the circle predicted ( $75 \%$ validity) the pitch of the auditory trigger cues.

During the third training session (320 trials), the subjects learned the following visuomotor associative task. One of the four shapes (IC) used during the first training session was presented for $300 \mathrm{msec}$. Each shape instructed the finger to be flexed, according to the rule learned during the first training session. The color of the shape was either green or red. A variable delay period (DP) followed $(0.1-5.1 \mathrm{sec}$ in steps of $0.5 \mathrm{sec})$. At the presentation of an auditory trigger cue (TC) (either 0.3 or $1.7 \mathrm{kHz}$, $300 \mathrm{msec}$ ), the subjects were required to provide the adequate response. The pitch of the trigger cues instructed the subjects either to flex the finger specified by the shape of the IC or to withhold the response. The color of the IC predicted ( $75 \%$ validity) the pitch of the auditory trigger

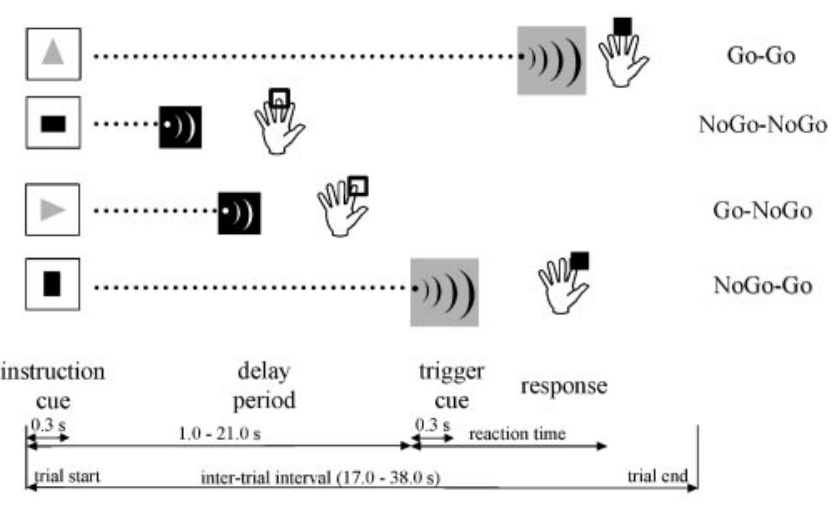

Figure 1. Diagram of the experimental task. One of the four shapes (instruction cue) was presented briefly $(300 \mathrm{msec})$. Subjects learned that two shapes instructed the subjects to flex the index finger; the other two shapes instructed the flexion of the middle finger. A variable delay (delay period, 1-21 sec in steps of $5 \mathrm{sec}$ ) was followed by a tone (trigger cue, 300 $\mathrm{msec}$ ). There were two auditory trigger cues with different pitch (indicated by black or gray background in this figure). One tone instructed the subjects to press the button specified by the shape of the instruction cue (indicated by the filled square). The other tone instructed the subject to withhold the response (indicated by the empty square). The color of the instruction cue (either red or green, corresponding to black or gray in the figure) predicted (overall 75\% validity; see Materials and Methods, Task) the Go/Nogo value of the forthcoming auditory trigger cue. Valid trials were labeled as Go-Go and Nogo-Nogo, whereas invalid trials were labeled as Go-Nogo and Nogo-Go.

cues. Subjects were informed that the pitch of the TC would instruct them either to move or to withhold the response. They were also informed that each of the two colors of the IC might have been preferentially associated with each of the two pitches of the TC. However, they were asked to determine the correct stimulus-response associations by trial and error. The combination of the different ICs and TCs generated four trial types: Go-Go, Nogo-Go, Go-Nogo, and Nogo-Nogo. The combinations between IC colors and TC pitches were counterbalanced across subjects.

The subjects were given 10 further trials of training in the scanner, just before the beginning of the scanning session. This allowed them to become familiar with the experimental setup while lying in the scanner.

During the scanning procedure (160 trials over eight sessions) (Fig. 1), the subjects performed the same visuomotor associative task practiced in the third training session. No feedback on performance was provided during the scanning session. The range of instructed delays was extended $(1.0-21.0 \mathrm{sec}$ in steps of $5 \mathrm{sec})$ to temporally disambiguate stimulus- and delay-related hemodynamic responses (Toni et al., 1999, 2002a). The task was performed continuously across the scanning sessions $(8.4 \mathrm{~min})$ as well as during intersession intervals $(\sim 5 \mathrm{~min})$. Unbeknownst to the subjects, the predictive value of the color of the IC on the pitch of the TC (i.e., the ratio between the number of valid and invalid trials) varied between the scanning sessions and the intersession intervals. During the scanning sessions, valid trials (Go-Go and Nogo-Nogo) and invalid trials (Nogo-Go and Go-Nogo) occurred in equal number, i.e., the predictive value of the color of the IC was null. During the intersession intervals, the proportion of valid trials was higher (85\%), i.e., the color of the IC provided above-chance predictions on the Go/Nogo value of the TC. This manipulation was introduced to satisfy two opposite requirements. On one hand, it was important to equalize the number of trials used to assess delay-related activity after $\mathrm{IC}_{\mathrm{Go}}$ and $\mathrm{IC}_{\text {Nogo }}$ stimuli. A systematic difference between $\mathrm{DP}_{\mathrm{Go}}$ and $\mathrm{DP}_{\mathrm{Nogo}}$ contingencies might have provided a biased statistical estimate of their relative differences. On the other hand, it was also important that the color of the IC remained a useful predictor of the Go or Nogo contingencies. Such constraint was important for achieving a robust behavioral effect, i.e., response time (RT) differences between Go-Go and Nogo-Go trials. Note however that this constraint is not a necessary requisite: significant electrophysiological correlates of motor preparation could be evoked even for equiprobable Go-Nogo contingencies (Low and Miller, 1999).

Image acquisition. The imaging procedures have been detailed elsewhere (Toni et al., 2002a). In brief, anatomical [MP-RAGE; echo time $(\mathrm{TE}) /$ repetition time $(\mathrm{TR})=4.5 / 11.4 \mathrm{msec}$; voxel size $=0.9 \times 0.9 \times 1.2$ 
$\mathrm{mm}$ ) and blood oxygen level-dependent (BOLD)-sensitive functional images (T2 ${ }^{*}$-weighted echo-planar imaging; TE/TR $=66 \mathrm{msec} / 4.2 \mathrm{sec}$; voxel size $=3.1 \times 3.1 \times 3.3 \mathrm{~mm} ; 30$ slices; 952 images in eight consecutive sessions) were acquired using a VISION scanner operating at 1.5 tesla (Siemens, Erlangen, Germany).

The experimental timing [mean intertrial interval (ITI) $=27.5 \pm 10.5$ sec, corresponding to $6.5 \pm 2.5 \mathrm{TRs}$ ] allowed us to characterize the evoked hemodynamic responses (EHRs) at a finer temporal resolution than the actual TR (Josephs et al., 1997; Toni et al., 2002a) while preserving a field of view over the whole brain.

The wide range of instructed delays (Fig. 1) allowed us to partition the EHRs into three independent components: one aligned with the instruction cue, one aligned with the trigger stimulus, and one extending over the delay period. The pseudorandom variation in the delay period between the instruction cue and the trigger stimulus ensured that the subjects could not anticipate the time of occurrence of the trigger cue. The extensive range of delays ensured that the subjects were ready to respond at any time after the presentation of the instruction cue. The pseudorandom presentation of different trial types ensured that the subjects could not anticipate the order of the conditions.

Image analysis. The data were analyzed with SPM99 (Statistical Parametric Mapping). Standard preprocessing procedures were applied (Toni et al., 1998, 1999). The statistical model consisted of independent partitions for each behavioral component of the task. We considered three task epochs (IC-, DP-, and TC-related activity), further subdivided into separate components according to the task contingencies (Go and Nogo for IC and DP; Go-Go, Go-Nogo, Nogo-Go, and Nogo-Nogo for TC). This scheme originated eight independent partitions, labeled as $\mathrm{IC}_{\mathrm{Go}}$, $\mathrm{IC}_{\text {Nogo }}, \mathrm{DP}_{\mathrm{Go}}, \mathrm{DP}_{\text {Nogo }}, \mathrm{TC}_{\mathrm{GoGo}}, \mathrm{TC}_{\mathrm{GoNogo}}, \mathrm{TC}_{\text {NogoGo }}$, and $\mathrm{TC}_{\text {NogoNogo }}$. Each partition represented an independent component of the same model with temporal basis functions [a canonical hemodynamic response function (Friston et al., 1998)] time locked to their occurrence. Delayrelated activities (i.e., $\mathrm{DP}_{\mathrm{Go}}$ and $\mathrm{DP}_{\mathrm{Nogo}}$ ) were time locked at the onset of the corresponding IC and extended over the delay period. DP-related activity is thus defined by a time interval rather than by a specific time point. We have previously characterized sustained preparatory activity with a flexible model requiring few assumptions on the timing and intensity of the EHRs (Toni et al., 2002a). In this study, we have adopted a more parsimonious approach, to emphasize statistical sensitivity over model flexibility.

Low-frequency signal drifts over time, residual head movementrelated effects, changes in mean signal over the whole brain, and overall differences across sessions and subjects were included in the model and considered as effects of no interest.

Statistical inference. The statistical significance of the estimated EHRs was assessed using $t$ statistics in the context of a multiple regression analysis. The null hypothesis was that the variance explained by a given regressor was consistent with the residual error, once the variance explained by the other components of the model was accounted for. Linear compounds (contrasts) were used to determine the effect associated with each behavioral component of the task, generating $t$ values for each voxel in the image, i.e., statistical parametric maps of $t$ values $[\operatorname{SPM}(t) \mathrm{s}]$. These contrast images indicate the spatial distribution of significant event-related activity for a given task component. We focused our analyses on specific sustained activity during the Go and Nogo trials $\left(\mathrm{DP}_{\mathrm{Go}}\right.$ and $\mathrm{DP}_{\text {Nogo }}$, i.e., DP-related activity after $\mathrm{IC}_{\mathrm{Go}}$ and $\mathrm{IC}_{\mathrm{Nogo}}$ stimuli, respectively). The specificity of DP-related activities was ensured by directly contrasting DP responses with the relative IC and TC activities (i.e., $\mathrm{DP}_{\mathrm{Go}}$ vs $\mathrm{IC}_{\mathrm{Go}} \mathrm{TC}_{\mathrm{GoGo}}$; $\mathrm{DP}_{\text {Nogo }}$ vs $\mathrm{IC}_{\text {Nogo }} \mathrm{TC}_{\text {NogoNogo }}$ ). In other words, the statistical search aimed at those voxels in which DP responses were stronger than IC or TC responses. This procedure ensured that the sustained responses were not contaminated by transient stimulus- or movement-related signals. By the same token, this procedure biased our search against those voxels showing both DP- and IC- (or TC-)related activities. However, because such criterion was applied at each and every voxel over the whole brain, it did not bias the search for regional patterns of DP-related activities.

We addressed the following relationships between $\mathrm{DP}_{\mathrm{Go}}$ and $\mathrm{DP}_{\text {Nogo }}$ : (1) $\mathrm{DP}_{\mathrm{Go}}>\mathrm{DP}_{\text {Nogo }}$; (2) $\mathrm{DP}_{\mathrm{Go}}=\mathrm{DP}_{\text {Nogo }}$; (3) $\mathrm{DP}_{\mathrm{Go}}<\mathrm{DP}_{\text {Nogo }}$ (see Table 1).

Differential motor preparatory activity $\left(\mathrm{DP}_{\mathrm{Go}}>\mathrm{DP}_{\text {Nogo }}\right)$ was assessed in two ways: (1) $\mathrm{DP}_{\mathrm{Go}}$ and $\mathrm{DP}_{\text {Nogo }}$ activities were directly compared $\left(\mathrm{DP}_{\mathrm{Go}} \mathrm{vs} \mathrm{DP}_{\text {Nogo }}\right)$; (2) differential preparatory activity $\left(\mathrm{DP}_{\mathrm{Go}} \mathrm{vs} \mathrm{DP}_{\text {Nogo }}\right)$ was isolated within the cerebral network showing $\mathrm{DP}_{\mathrm{Go}}$ activity over and above transient IC- or TC-related activity for the same trial type $\left(\mathrm{DP}_{\mathrm{Go}}\right.$ vs $\left.\mathrm{IC}_{\mathrm{Go}} \mathrm{TC}_{\mathrm{GoGo}}\right)$.

Delay-related activity independent from the amount of motor preparation $\left(\mathrm{DP}_{\mathrm{Go}}=\mathrm{DP}_{\text {Nogo }}\right)$ was assessed through a multiple masking procedure between DP-related activities expressed during the Go and Nogo trials, over and above transient IC- or TC-related activity [(DP ${ }_{\mathrm{Go}} \mathrm{vs}$ $\left.\mathrm{IC}_{\mathrm{Go}} \mathrm{TC}_{\mathrm{GoGo}}\right)$ and $\left.\left(\mathrm{DP}_{\text {Nogo }} \mathrm{vs}_{\mathrm{IC}_{\text {Nogo }}} \mathrm{TC}_{\text {NogoNogo }}\right)\right]$. The inference here is about the probability of having delay-related activity after either $\mathrm{IC}_{\mathrm{Go}}$ or $\mathrm{IC}_{\text {Nogo }}$ stimuli that co-occurs in the same voxel (Friston et al., 1996). In other words, this analysis assessed common and comparable activities across the two delay periods.

Higher activity during $\mathrm{DP}_{\text {Nogo }}$ than $\mathrm{DP}_{\mathrm{Go}}$ was assessed through the following comparisons: (1) $\mathrm{DP}_{\text {Nogo }}$ and $\mathrm{DP}_{\mathrm{Go}}$ activities were directly compared (DP $\mathrm{Nogo}_{\text {vs }} \mathrm{DP}_{\mathrm{Go}}$; (2) differential activity between $\mathrm{DP}_{\text {Nogo }}$ and $\mathrm{DP}_{\mathrm{Go}}$ was isolated within the cerebral network showing $\mathrm{DP}_{\text {Nogo }}$ activity over and above transient IC- or TC-related activity for the same trial type $\left(\mathrm{DP}_{\text {Nogo }}\right.$ vs $\left.\mathrm{IC}_{\text {Nogo }} \mathrm{TC}_{\text {NogoNogo }}\right)$.

Gaussian field theory allowed us to make inferences corrected for the number of nonindependent comparisons (Friston et al., 1995b). The effective degrees of freedom of the error term took into account the temporal autocorrelation of the data (Friston et al., 1995a). Contrast images $[\operatorname{SPM}(t) \mathrm{s}]$ were masked by a smooth group average of segmented graymatter mean $\mathrm{T} 2 *$ images. This procedure ensured that only gray-matter voxels were included in the results.

We report the results of a fixed-effect group analysis. The inferences we provide are about the presence of an effect in these subjects during these scanning sessions and not about the average size of the effect in the population from which the subjects were drawn (Friston et al., 1999a,b). The statistical threshold used ( $p<0.05$ corrected for search volume) was $\operatorname{SPM}\left(t_{4519}\right)>4.57\left[\operatorname{SPM}\left(t^{2}{ }_{4519}\right)>3.05\right.$ for the conjunction analysis]. In addition to this exploratory analysis, we also tested our null hypotheses on volumes of interests (VOIs). We have used VOIs objectively defined on the basis of functional-anatomical information obtained in previous, related experiments (Toni et al., 1999) and extending over the full-width half-maximum of the $\operatorname{SPM}(t)(13 \mathrm{~mm})$. This procedure ensures an enhanced sensitivity (reduced type II errors) without affecting the specificity of the results. The statistical threshold used in these anatomically constrained analyses was $p<0.05$ corrected for the search volume over each VOI.

Anatomical details of significant signal changes were obtained by superimposing the $\operatorname{SPM}(t)$ s on both the structural and mean functional images of each subject. The atlases of Duvernoy et al. (1991), Ono et al. (1990), and Schmahmann et al. (1999) were used to identify relevant anatomical landmarks.

Behavioral analysis. The mean RTs and median error rates were measured for the trials performed during the scanning sessions. RTs and error rates were compared (two-tailed paired $t$ test; $p<0.01$ ) across experimental conditions $\left(\mathrm{TC}_{\mathrm{GoGo}}, \mathrm{TC}_{\mathrm{NogoGo}}\right)$. Furthermore, to assess response homogeneity across time and delays, RTs were linearly regressed over two different explanatory variables: experimental time (session 1-8) and length of the delay period (1.0-21.0 sec in five steps of $5 \mathrm{sec}$ ). Analysis of regression assessed the significance of the slope $(p<0.01)$.

EMG and eye position recordings were examined off-line. Means and SDs of at least 16 artifact-free trials were measured for each subject during the delay period across the two experimental conditions (i.e., time interval between the offset of the visual instruction cue and the onset of the auditory trigger cue during either $\mathrm{DP}_{\mathrm{Go}}$ or $\mathrm{DP}_{\text {Nogo }}$ trials). Paired $t$ tests assessed the significance of the experimental manipulation $(p<$ 0.05 ; two-tailed distribution).

\section{RESULTS}

\section{Task performance}

The subjects were debriefed at the end of the experiment. They consistently (six of six) reported to have performed the task without considering the color of the IC, because they thought it did not provide reliable information on the instruction conveyed by the following TC.

In contrast with their belief, there was a significant difference in RTs across conditions [Go-Go: $484 \pm 34 \mathrm{msec}($ mean $+\mathrm{SD})$; Nogo-Go: $\left.567 \pm 31 \mathrm{msec} ; t_{(5)}=7.63 ; p<0.01\right]$ (Fig. $2 A$ ). This effect could not be explained by differential error rates [Go-Go: 

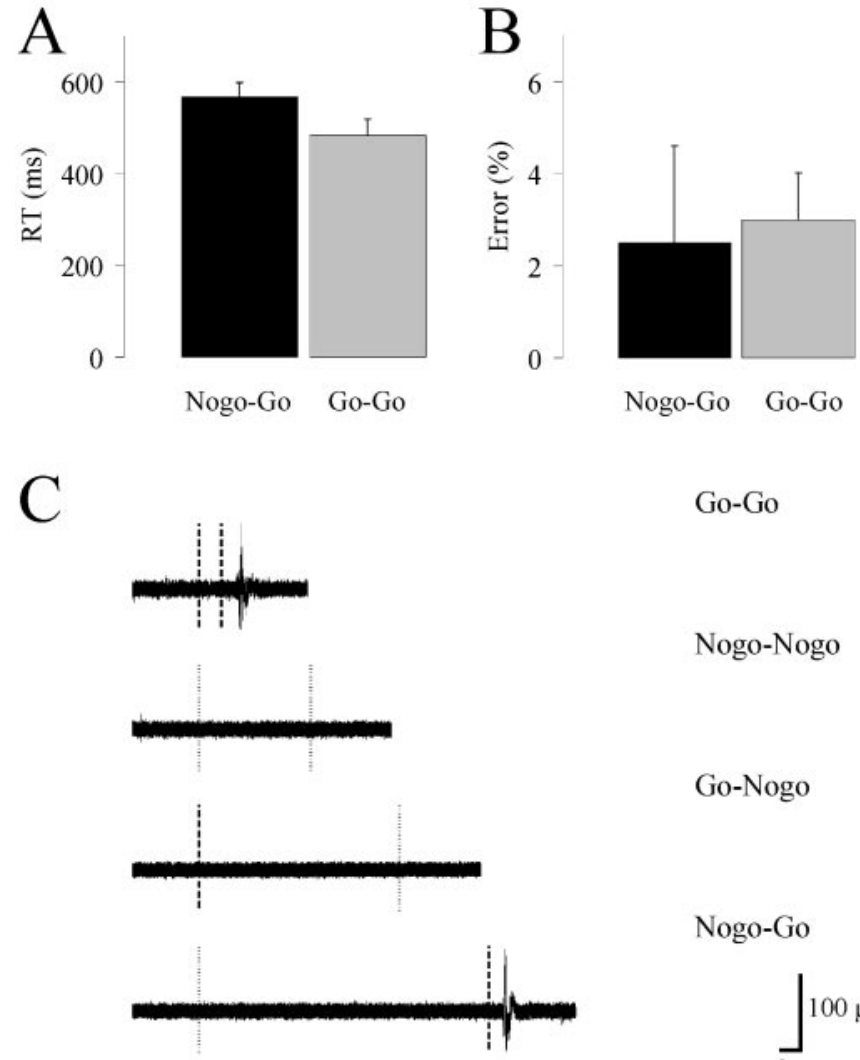

Go-Go

Nogo-Nogo

Go-Nogo

Nogo-Go

$\int_{1 \mathrm{~s}} 100 \mu \mathrm{V}$

$\mathrm{D}$

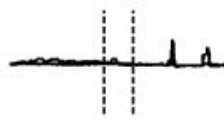

Go-Go
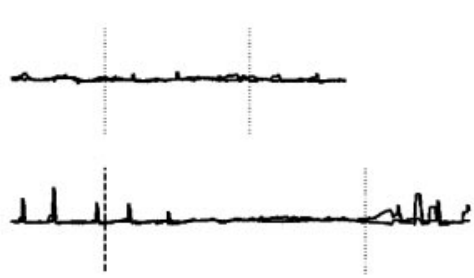

Go-Nogo

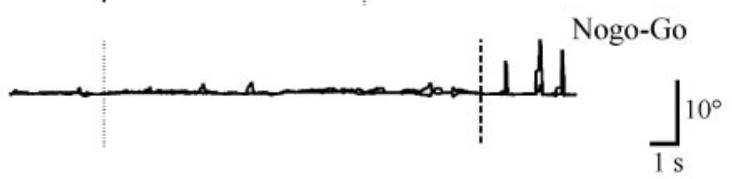

Figure 2. Behavioral data. $A$, Reaction times $(R T)$ (mean $\pm \mathrm{SE}$ ); $B$, error rate measured in the Go-Go (black histogram) and Nogo-Go (gray histogram) conditions; $C$, representative EMG; $D$, eye position recording from four individual trials in a single subject. Left column, Vertical dashed or dotted lines represent the onset of the Go or Nogo visual instruction cues, respectively. Right column, Vertical dashed or dotted lines represent the onset of the Go or Nogo auditory trigger cues, respectively.

$3.0 \pm 1.0 \%($ median $+\mathrm{SD}) ;$ Nogo-Go $2.5 \pm 2.1 \% ; t_{(5)}=0.78 ; p>$ 0.4] (Fig. 2B). The RTs, averaged over each session for each subject, did not show any consistent trend as a function of experimental time or length of delay, consistent with our previous reports (Toni et al., 2002a,b). This indicates that the unpredictable timing of the TC avoided response anticipation and homogeneously triggered motor preparation across the whole range of delays and scanning time.
We have shown previously (Toni et al., 2002a) that in this experimental setup, skeletomotor and oculomotor activities do not contaminate DP-related activity. EMG and eye-position measurements confirmed our previous findings (Fig. $2 C, D$ ). The subjects performed the task according to the instructions, providing an overt response only after the presentation of the appropriate trigger cue. Eye position measurements confirmed that task performance did not affect the pattern of gaze displacements across experimental epochs and conditions. In particular, there were no differential tonic shifts of the gaze, nor were there differential numbers of eye movements between the two delay periods $\left[\mathrm{DP}_{\mathrm{Go}}\right.$ : $1.4,1.4 \pm 0.9,0.8^{\circ}$ (mean $\times$ coordinate, mean $y$ coordinate $\pm \mathrm{SE}$ $x$, SE $y$ ); 16.2, $11.1 \pm 1.6,1.6^{\circ}$ (mean $\times$ variability, mean $y$ variability $\pm \mathrm{SE} x, \mathrm{SE} y) ; \mathrm{DP}_{\mathrm{Nogo}}: 1.3,1.2 \pm 0.5,0.7^{\circ} ; 14.8,11.1 \pm$ $\left.1.8,2.4^{\circ}\right]$.

\section{Statistical parametric maps}

The following section describes the $\operatorname{SPM}(t)$ s associated with each of the three comparisons of interest of the study (Table 1). Significant differential activations are listed in Tables 2, 3, and 4 and illustrated in Figure 3.

Specific differential motor preparatory activity $\left(\mathrm{DP}_{\mathrm{Go}}\right.$ vs $\mathrm{DP}_{\text {Nogo }}$ ) was found in the right cerebellar cortex and in right prefrontal cortex. Figure $3 C$ (green clusters) provides anatomical details for the responses evoked in lobule $\mathrm{HV} / \mathrm{HVI}$ of the cerebellum. Comparison of $\mathrm{DP}_{\mathrm{Go}}$ versus $\mathrm{IC}_{\mathrm{Go}} \mathrm{TC}_{\mathrm{GoGo}}$ (masked by $\mathrm{DP}_{\mathrm{Go}} \mathrm{vs}_{\mathrm{DP}} \mathrm{Nogo}_{\mathrm{o}}$ ) revealed additional preparatory activities in the left putamen, in the claustrum, and in extrastriate, mediotemporal, and frontal cortex. Figure 3 (green clusters) provides anatomical details for the responses evoked in the anterior portion of the left putamen (Fig. 3G), along the left hippocampus (Fig. 3G), in the dorsal precentral gyrus (Fig. $3 J$ ), and in the right inferior frontal sulcus and left superior frontal sulcus (Fig. 3M).

Specific DP-related activity uncorrelated with the likelihood of

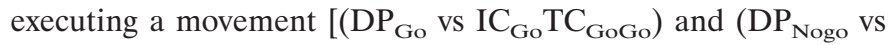
$\left.\left.\mathrm{IC}_{\text {Nogo }} \mathrm{TC}_{\text {NogoNogo }}\right)\right]$ was found in a set of cortical and subcortical areas often contiguous to those showing preparatory activity. Common and comparable activities across the two delay periods were found bilaterally at the level of the putamen and in temporal, parietal, and frontal cortices. $\mathrm{DP}_{\mathrm{Go}}$ and $\mathrm{DP}_{\text {Nogo }}$ evoked similar activities in the anterior third of the right superior frontal sulcus, in the left pars opercularis and right pars orbitalis of the inferior frontal gyrus, along the superior ramus of the left precentral gyrus (Fig. 3J, yellow clusters), in the paracentral ramus of the left cingulate sulcus, bilaterally along the anterior and middle thirds of the intraparietal sulcus (Fig. $3 G, J$ ), on the left superior parietal lobule, bilaterally along the middle third of the superior temporal gyrus, on the right parahippocampal gyrus, and bilaterally in the hippocampus (Fig. $3 C, J$ ).

Stronger evoked hemodynamic responses during $\mathrm{DP}_{\mathrm{Nogo}}$ as compared with $\mathrm{DP}_{\mathrm{Go}}$ were found in two confined regions of extrastriate cortex. Inspection of their time courses showed a stronger reduction of BOLD signal during $\mathrm{DP}_{\mathrm{Go}}$ than $\mathrm{DP}_{\mathrm{Nogo}}$. In the absence of a priori hypothesis on this activity pattern, this particular result will not be explored further in this report. Sustained activity expressed during the delay period of Nogo

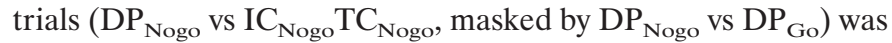
found at the level of parietal and premotor cortices, mainly in the left hemisphere. $\mathrm{DP}_{\text {Nogo }}$ evoked responses along the superior ramus of the precentral sulcus (Fig. $3 G, J$, red clusters), in the paracentral ramus of the cingulate sulcus, along the anterior and 
Table 1. Comparisons between $\mathrm{DP}_{\mathrm{Go}}$ and $\mathrm{DP}_{\text {Nogo }}$

Functional relationship

Motor preparation

$\left(\mathrm{DP}_{\mathrm{Go}}>\mathrm{DP}_{\text {Nogo }}\right)$

Motor intention

$\left(\mathrm{DP}_{\mathrm{Go}}=\mathrm{DP}_{\text {Nogo }}\right)$

Motor inhibition

$\left(\mathrm{DP}_{\mathrm{Nogo}}>\mathrm{DP}_{\mathrm{Go}}\right)$
Contrast

$\mathrm{DP}_{\mathrm{Go}}$ versusDP $\mathrm{Nogo}_{\mathrm{O}}$

$\mathrm{DP}_{\mathrm{Go}}$ versus $\mathrm{IC}_{\mathrm{Go}} \mathrm{TC}_{\mathrm{Go}}$ masked by $\mathrm{DP}_{\mathrm{Go}}$ versus $\mathrm{DP}_{\mathrm{Nogo}}$

$\mathrm{DP}_{\mathrm{GoR} \text { versus } \mathrm{IC}_{\mathrm{Go}}} \mathrm{TC}_{\mathrm{Go}}$ and $\mathrm{DP}_{\text {Nogo }}$ versus $\mathrm{IC}_{\mathrm{Nogo}} \mathrm{TC}_{\text {NogoNogo }}$

$\mathrm{DP}_{\text {Nogo }}$ versus $\mathrm{DP}_{\mathrm{Go}}$

$\mathrm{DP}_{\text {Nogo }}$ versus $\mathrm{IC}_{\text {Nogo }} \mathrm{TC}_{\text {Nogo masked by DP }} \mathrm{P}_{\text {Nogo }}$ versus $\mathrm{DP}_{\text {Nogo }}$

Table 2. Differential motor preparatory activity $\left(\mathrm{DP}_{\mathrm{Go}}>\mathrm{DP}_{\mathrm{Nogo}_{\mathrm{o}}}\right)$

\begin{tabular}{|c|c|c|}
\hline Anatomical region & Stereotactic coordinates & $Z$ value \\
\hline \multicolumn{3}{|c|}{$\mathrm{DP}_{\mathrm{Go}}$ versus $\mathrm{DP}_{\text {Nogo }}$} \\
\hline \multicolumn{3}{|l|}{ Superior frontal sulcus } \\
\hline Anterior third & $22,66,0$ & 4.68 \\
\hline Lateral orbital sulcus & $36,54,-10$ & 5.18 \\
\hline Cerebellum & $28,-46,-34$ & 4.81 \\
\hline \multicolumn{3}{|c|}{$\mathrm{DP}_{\mathrm{Go}}$ versus $\mathrm{IC}_{\mathrm{Go}} \mathrm{TC}_{\mathrm{GoGo}}$ masked by $\mathrm{DP}_{\mathrm{Go}}$ versus $\mathrm{DP}_{\text {Nogo }}$} \\
\hline \multicolumn{3}{|l|}{ Superior frontal sulcus } \\
\hline Middle third & $-20,30,42$ & 5.59 \\
\hline \multicolumn{3}{|l|}{ Cingulate sulcus } \\
\hline Anterior third & $12,46,4$ & 5.82 \\
\hline \multicolumn{3}{|l|}{ Inferior frontal gyrus } \\
\hline Pars orbitalis & $48,34,-10$ & 6.03 \\
\hline Lateral convexity & $54,32,4$ & 4.67 \\
\hline Precentral gyrus & $-10,8,60$ & $3.43^{*}$ \\
\hline Hippocampus & $34,-16,-24$ & 6.57 \\
\hline Head & $-32,-16,-24$ & 5.60 \\
\hline Body & $-26,-34,-14$ & 6.75 \\
\hline Tail & $-18,-42,0$ & 6.48 \\
\hline Superior temporal sulcus & $-58,-14,-22$ & $>8$ \\
\hline Middle third & $58,-10,-22$ & $>8$ \\
\hline Posterior third & $-52,-34,2$ & 5.38 \\
\hline \multirow[t]{2}{*}{ Claustrum } & $-34,10,-14$ & 5.16 \\
\hline & $34,12,-18$ & 5.08 \\
\hline Putamen & $-28,8,2$ & 4.97 \\
\hline
\end{tabular}

${ }^{*} p<0.05$ corrected for VOI search volume.

posterior thirds of the intraparietal sulcus, and in the superior parietal lobule.

\section{Evoked hemodynamic responses}

The following section characterizes the evoked hemodynamic responses of some relevant areas. The experimental design allowed us to distinguish the percentage adjusted BOLD signal associated with the IC, the DP, or the TC (Fig. 1). IC- and DP-related activities were further subdivided according to the task contingencies in two categories each $\left(\mathrm{IC}_{\mathrm{Go}}, \mathrm{IC}_{\mathrm{Nogo}}, \mathrm{DP}_{\mathrm{Go}}\right.$, $\left.\mathrm{DP}_{\text {Nogo }}\right)$. TC-related activities were subdivided into four categories, according to the combination of instruction and trigger cues $\left(\mathrm{TC}_{\mathrm{GoGo}}, \mathrm{TC}_{\mathrm{GoNogo}}, \mathrm{TC}_{\text {NogoGo }}, \mathrm{TC}_{\text {NogoNogo }}\right)$.

\section{EHRs associated with specific preparatory activity}

$\left(D P_{G o}>D P_{\text {Nogo }}\right)$

Figure $3 E$ illustrates the EHRs for a local maximum in lobule $\mathrm{HV} / \mathrm{HVI}$ of the cerebellar cortex. This anatomical region showed a specific sustained response during the delay period after a "Go" instruction cue (in green). The specificity of the former response can be appreciated when compared with the EHR evoked during the same instructed delays, but after a "Nogo" instruction cue (in red). Furthermore, there was a clear movement-related response ( $\mathrm{TC}_{\mathrm{GoGo}}$ in gray), but no response after $\mathrm{TC}_{\mathrm{GoNogo}}$ (in black). Finally, it can be seen that there was no consistent IC-related activity $\left(\mathrm{IC}_{\mathrm{GoGo}}\right.$, in blue). The anatomical location and the signal strength of the former pattern of activities can be compared with that shown in Figure $3 D$. This cluster $(22,-54,-24)$ emerged from the contrast between activity time-locked to $\mathrm{TC}_{\mathrm{GoGo}}$ and activity time-locked to $\mathrm{TC}_{\mathrm{GoNogo}}$. Therefore, this comparison isolates movement-related signals, having controlled for the instruction- and preparatory-related activities of the task. There was a clear, strong, movement-related response during Go-Go trials (curve in gray), a weaker response during Nogo-Go trials (curve in magenta), and an even weaker response time-locked to the TC during Go-Nogo trials (curve in black). This cerebellar cluster did not show any IC- or DP-related responses.

Differential preparatory activity $\left(\mathrm{DP}_{\mathrm{Go}}>\mathrm{DP}_{\text {Nogo }}\right)$ emerged also at the level of the head of the right hippocampus. Figure $3 B$ shows 
Table 3. Delay-related activity independent from the amount of motor preparation $\left(\mathrm{DP}_{\mathrm{Go}}=\mathrm{DP}_{\mathrm{Nogo}}\right)$

Superior frontal sulcus
Anterior third
Inferior frontal gyrus
Pars opercularis
Pars orbitalis
Cingulate sulcus
Paracentral ramus
Precentral sulcus
Superior ramus
Intraparietal sulcus
Anterior third
Middle third

Superior parietal lobule
Parahippocampal gyrus
Hippocampus
Head
Body
Tail
Superior temporal sulcus
Middle third

Putamen
$\mathrm{DP}_{\mathrm{Go}}$ versus $\mathrm{IC}_{\mathrm{Go}} \mathrm{TC}_{\mathrm{GoGo}}$ and $\mathrm{DP}_{\text {Nogo }}$ versus $\mathrm{IC}_{\mathrm{Nogo}} \mathrm{TC}_{\text {NogoNogo }}$

5.08

$-44,34,-16 \quad 4.79$

$48,42,-16 \quad 4.71$

$\begin{array}{ll}-6,2,54 & 5.66\end{array}$

$-22,8,56 \quad 5.51$

$-16,6,66 \quad 5.42$

$\begin{array}{ll}-30,-48,48 & 7.50\end{array}$

$34,-44,46 \quad 4.75$

$-32,-64,42 \quad 4.87$

$34,-60,42 \quad 7.01$

$46,-56,36 \quad 5.06$

$\begin{array}{ll}-18,-54,60 & 4.75\end{array}$

$30,-34,-18 \quad 6.84$

$24,-12,-22$

$-32,-24,-18 \quad 5.94$

$-22,-38,-2 \quad 5.06$

$52,-14,-24 \quad 5.70$

$62,-14,-12 \quad 4.76$

$-56,-18,-22 \quad 5.44$

$34,-8,6 \quad 5.27$

$-30,-2,6 \quad 4.89$

Table 4. Differential delay-related activity $\left(\mathrm{DP}_{\text {Nogo }}>\mathrm{DP}_{\mathrm{Go}}\right)$

\begin{tabular}{|c|c|c|}
\hline Anatomical region & Stereotactic coordinates & $Z$ value \\
\hline \multicolumn{3}{|c|}{$\mathrm{DP}_{\text {Nogo }}$ versus $\mathrm{DP}_{\mathrm{Go}}$} \\
\hline \multicolumn{3}{|l|}{ Occipito-parietal fissure } \\
\hline medial portion & $4,-76,38$ & 4.70 \\
\hline Lingual gyrus & $-4,-92,2$ & 4.79 \\
\hline \multicolumn{3}{|c|}{$\mathrm{DP}_{\text {Nogo }}$ versus $\mathrm{IC}_{\text {Nogo }} \mathrm{TC}_{\text {NogoNogo }}$ masked by $\mathrm{DP}_{\text {Nogo }}$ versus $\mathrm{DP}_{\mathrm{Go}}$} \\
\hline \multicolumn{3}{|l|}{ Cingulate sulcus } \\
\hline Paracentral ramus & $-8,-4,50$ & 4.78 \\
\hline \multicolumn{3}{|l|}{ Precentral sulcus } \\
\hline \multirow[t]{2}{*}{ Superior ramus } & $-32,-14,62$ & 6.33 \\
\hline & $-24,-10,66$ & 4.63 \\
\hline \multicolumn{3}{|l|}{ Intraparietal sulcus } \\
\hline \multirow[t]{2}{*}{ Anterior third } & $-36,-44,48$ & 6.63 \\
\hline & $-44,-24,56$ & 5.00 \\
\hline Posterior third & $40,-60,42$ & 4.69 \\
\hline Superior parietal lobule & $-32,-56,60$ & 4.62 \\
\hline
\end{tabular}

that sustained activity was expressed during the DP of both trial types, but more strongly after the Go (curve in green) than the Nogo (curve in red) instruction cues. There was also a BOLD signal decrease time-locked to the TC during the Nogo-Go trial (curve in magenta). This latter response is unlikely to be directly associated with the performance or inhibition of a movement, because there were no TC-related responses during the Go-Go and Go-Nogo trials (Fig. 3B, curves in gray and black, respectively).
Preparatory activity was found at the level of the left dorsorostral putamen (Fig. $3 F, G$ ). The specific sustained preparatory response (green curve) is significant against the smaller response obtained during the delay periods after "Nogo" instruction cues (red curve). Furthermore, this subcortical cluster showed a movement-related response during "Go-Go" trials (gray curve).

Two regions of the prefrontal cortex showed significant preparatory activities, as illustrated in Figure $3 L-N$. A cluster along the 

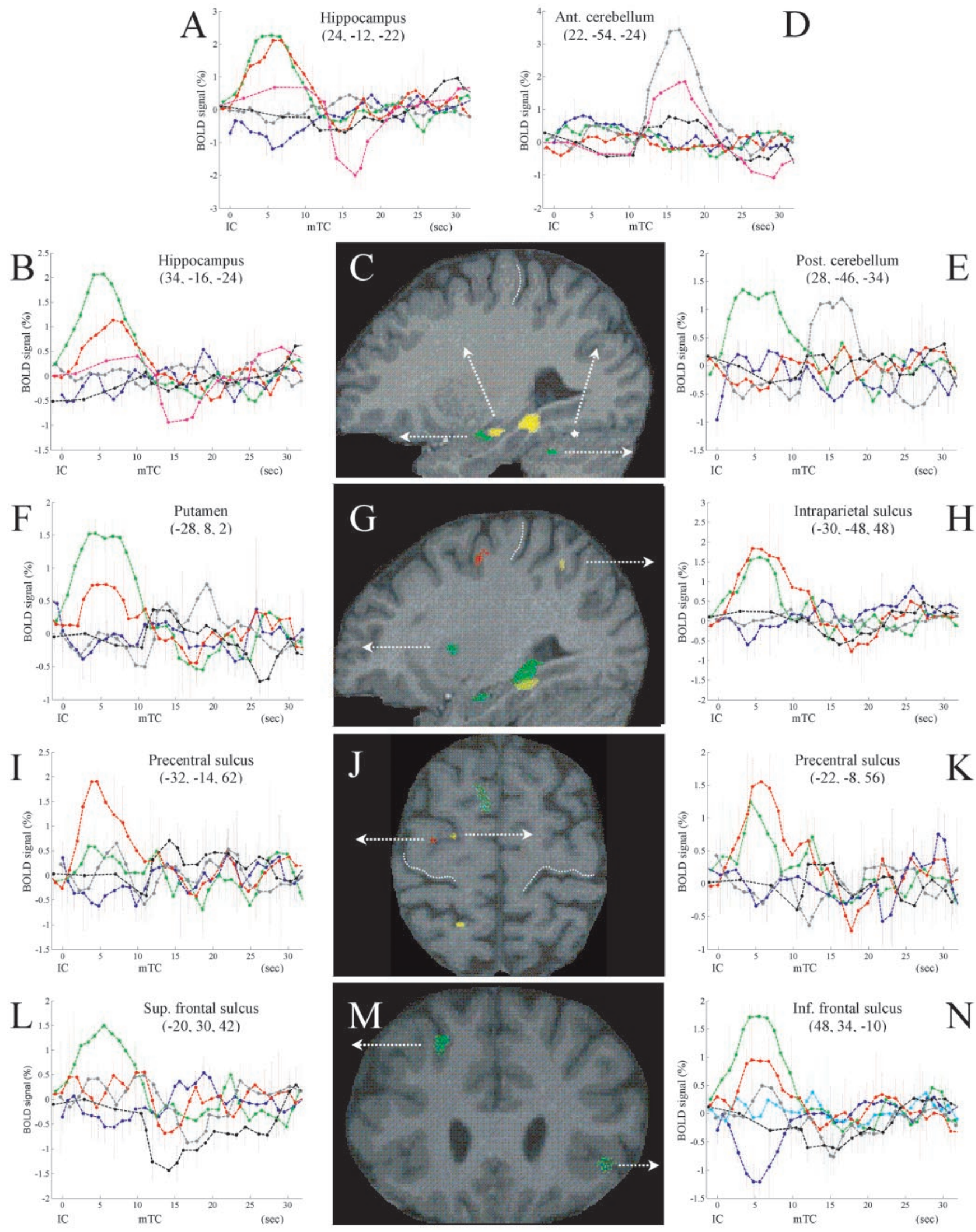

Figure 3. Time course and anatomical localization of significant differential evoked hemodynamic responses. Curves show percentage BOLD signal (mean adjusted group data $\pm \mathrm{SE}$ ) as a function of time and their anatomical localization. The curves represent responses time-locked either to the instruction cue (IC- and DP-related responses) or to the trigger cue (TC-related responses): in blue, IC-related activity (Figure legend continues.) 
middle third of the superior frontal sulcus (Fig. $3 L, M$ ) responded during the delay periods after Go instruction cues (green curve). The responses to the other epochs and components of the task were within the statistical noise of the baseline, apart from a BOLD signal decrease time-locked to the TC during Go-Nogo trials (black curve). Preparatory responses emerged also at the level of the pars orbitalis of the inferior frontal gyrus (Fig. $3 M, N$ ). In this cluster, the specific preparatory activity (green curve) was significant against a weaker but present DP-related response during Nogo trials (Fig. $3 N$, curve in red). The responses to the other epochs and components of the task were within the statistical noise of the baseline, apart from a BOLD signal decrease time-locked to the IC during Go trials (Fig. $3 N$, curve in blue). This appeared to be a specific effect, because no IC-related response can be seen during the corresponding "Nogo" trials (curve in cyan).

\section{EHRs independent from the level of response preparation} $\left(D P_{G o}=D P_{\text {Nogo }}\right)$

Comparable levels of activity during the delay period of both Go and Nogo trials $\left(\mathrm{DP}_{\mathrm{Go}}=\mathrm{DP}_{\text {Nogo }}\right)$ emerged along the head of the right hippocampus (Fig. $3 A, C$, cluster in yellow), anatomically close to a cluster with preparatory activity (Fig. $3 B, C$, cluster in green). Interestingly, despite different DP-related responses, both clusters showed a similar decrease in BOLD signal, time-locked to the TC during Go-Nogo trials (Fig. $3 A, B$, curves in magenta).

Significant DP-related activity independent from the likelihood of performing a movement was found at several locations along the intraparietal sulcus (Table 3). Figure 3, $G$ and $H$, illustrates the anatomical location and signal time course of one of these clusters. There were significant and overlapping responses during the delay period of both Go and Nogo trials (Fig. $3 H$, curves in green and red). The responses to the other epochs and components of the task oscillate within the statistical noise of the baseline. A similar pattern of responses was found more anteriorly, at the level of the superior ramus of the precentral sulcus (Fig. 3J,K).

\section{EHRs associated with tonic response inhibition}

$\left(D P_{\text {Nogo }}>D P_{G o}\right)$

Figure 3, $I$ and $J$, illustrates the anatomy and BOLD signal time course of a cluster with a stronger response during $\mathrm{DP}_{\text {Nogo }}$ than $\mathrm{DP}_{\mathrm{Go}}$ (see also Fig. $3 G$ ). DP-related activity emerged only during Nogo trials (curve in red). However, a weak TC-related response can also be detected during Go-Nogo trials (curve in black). Note that this pattern of activity is anatomically contiguous to a cluster with a different set of responses (Fig. $3 J, K$ ).

\section{DISCUSSION}

In this experiment we have parcellated the neural correlates of delay-related activity after an instruction cue and preceding a motor response into three functional components. By modulating response probability, we have characterized the functional anatomy of movement-dependent DP activity (motor preparation and motor inhibition) as compared with DP activity unaffected by response probability (motor intention).

DP activity was found not only in frontal and parietal regions, but also in several other telencephalic structures (Table 2). Regions expressing motor intentions and preparatory responses were intermingled, except for posterior parietal cortex where DP activity was found regardless of response likelihood (Table 3). In contrast to the distributed nature of preparatory and intentional activities, tonic inhibitory responses emerged only in a circumscribed and lateralized frontoparietal circuit (Table 4).

\section{Behavioral performance}

This experiment is concerned with the neural basis of motor cognitive processes in the context of prelearned visuomotor associations. Our experimental manipulation, aimed at varying the degree of motor preparation elicited during the DP, induced a significant effect on RTs (Fig. $2 A$ ) independent from error rates (Fig. 2B). A virtually error-free performance indicates that the information on the movement to be performed was carried over the delay independently from the likelihood of using such information. The homogeneous error rate across conditions excludes disparities in movement selection: equally correct stimulus-driven choices were made in response to both Go and Nogo instruction cues. Finally, the effect of the RTs was not contaminated by overt expectations or movements. The subjects reported that they were unaware of the critical experimental manipulation, and electrophysiological controls excluded differential finger or eye movements across the DP of Go and Nogo trials.

It might be argued that the DP was crossed by holding in memory the IC, rather than preparing a motor response. However, the former strategy would have generated RTs that were a function of delay length (Toni et al., 2002b). Conversely, the independence of RTs from the length of the delay period is consistent with DP-related responses reflecting motor preparatory activity, rather than sensory or memory phenomena (Ilan and Miller, 1998).

It is possible that the $\mathrm{IC}_{\mathrm{Go}}$ and $\mathrm{IC}_{\mathrm{Nogo}}$ stimuli elicited different amounts of sustained attention during the DP and different amounts of selective attention to the TC. Accordingly, the TC might have been detected or identified later after $\mathrm{IC}_{\text {Nogo }}$ than $\mathrm{IC}_{\mathrm{Go}}$ stimuli. In this perspective, the RT costs we found would reflect differences in sustained and selective attention to the auditory trigger cue, rather than differences in motor preparation. Our behavioral analysis cannot distinguish between these two possibilities. However, attentional processes produce robust modulations of activity in primary sensory areas (Kastner et al., 1999; Gilbert et al., 2000; Macaluso et al., 2002). No differential effects in or around auditory regions were found when either TC- or DP-related responses were compared directly. Although such a

\section{$\leftarrow$}

(Figure legend continued.) (Go trials); in cyan, IC-related activity (Nogo trials); in green, DP-related activity (Go trials); in red, DP-related activity (Nogo trials); in gray, TC-related activity (Go-Go trials); in black, TC-related activity (Go-Nogo trials); in magenta, TC-related activity (Nogo-Go trials). Signals from local maxima are as follows: $A$, head of hippocampus, ventrorostral sector $(24,-12,-22) ; B$, head of hippocampus, dorsocaudal sector ( 34 , $-16,-24) ; D$, anterior cerebellum, lobule V $(22,-54,-24) ; E$, posterior cerebellum, lobule V I $(28,-46,-34) ; F$, putamen, dorsorostral sector $(-28$, $8,2) ; H$, intraparietal sulcus, anterior third $(-30,-48,48) ; I$, precentral sulcus, superior ramus $(-32,-14,62) ; K$, precentral sulcus, superior ramus $(-22$, $-8,56) ; L$, superior frontal sulcus, middle third $(-20,30,42) ; N$, inferior frontal sulcus, pars orbitalis $(48,34,-10)$. In $B, G, J$, and $M$, the SPM $(t) \mathrm{s}$ for the relevant contrasts have been superimposed on a representative brain (in green: $\mathrm{DP}_{\mathrm{Go}}>\mathrm{DP}_{\text {Nogo }}$; in yellow: $\mathrm{DP}_{\mathrm{Go}}=\mathrm{DP}_{\mathrm{Nogo}} ;$ in red: $\mathrm{DP}_{\mathrm{Go}}<\mathrm{DP}_{\mathrm{Nogo}}$; in white: $\left.\mathrm{TC}_{\mathrm{GoGo}}>\mathrm{TC}_{\mathrm{GoNogo}}\right) . B$, Parasagittal section $(x=28) ; G$, parasagittal section $(x=-28) ; J$, transverse section $(z=62) ; M$, coronal section $(y=$ 30). The white dotted lines mark the rostral bank of the central sulcus. 
negative result awaits further confirmatory evidence, it appears unlikely that differential expectations of a sensory event constitute the main drive behind our DP-related activities.

On these empirical bases and assuming that increased motor preparation reduces the duration of motor processing after TC onset (Crammond and Kalaska, 2000; Miller and Low, 2001), we can interpret the difference in RTs between Go-Go and Nogo-Go trials as reflecting differences in preparatory activity expressed during the DP.

Despite such a difference in RTs, the subjects consistently reported that they performed the task without considering the color of the IC. How can we explain this surprising result? First, the extensive training procedure was based mainly on trial-anderror learning rather than verbal instructions. Such an approach is likely to have taxed procedural rather than declarative mechanisms. Second, the crucial experimental manipulation [timemodulated pseudorandom associations between IC (color) and TC (pitch)] appeared to be irrelevant for correct task performance (Fig. $2 B$ ) but beneficial for speeding subjects' responses (Fig. 2A). Accordingly, it is likely that the color of the IC was used as a context variable rather than a decision variable. In summary, the stochastic and contextual nature of task manipulations might have contributed to prevent their overt detection.

\section{Posterior parietal cortex}

Intraparietal and superior parietal regions were responsive during DP (Fig. $3 G, J$ ), regardless of the likelihood of executing a movement. These responses were unlikely to have been driven by the saliency of the IC (Kusunoki et al., 2000), because there were no sensory stimuli during DP. Some parietal regions can display mnestic activity (Chafee and Goldman-Rakic, 1998; Rowe et al., 2000), but sensory memories cannot explain our behavioral results (Toni et al., 2002b). Inhibitory responses have been reported in parietal cortex (Garavan et al., 1999), but such responses should have been most evident during Go-Nogo trials, when time-locked to the TC [Fig. $3 H$ (note the flat black curve; in these trials the subjects withheld the response, despite having being precued to provide it)]. Finally, this parietal DP activity might reflect anticipation of the sensory consequences of intended actions (Duhamel et al., 1992), but there was no response timelocked to TC during Go-Go trials (Fig. 3H, gray curve). Rather, our results provide further support for the suggestion that outcome or response probability can influence decision processes before a sensory instruction has identified the correct response (Platt and Glimcher, 1999). Our manipulation of response probabilities shares some features with the study of Platt and Glimcher (1999). However, here we have temporally segregated such manipulations from the neural recordings. During the scanning sessions there was no feedback on performance or imbalances between response probabilities. Overall, our inference extends the scope of previous electrophysiological reports based on single units with directionally selective motor responses (Kalaska and Crammond, 1995; Snyder et al., 1997; Cisek and Kalaska, 2002), insofar as imaging studies can take into account those majorities of cells with DP activity but without selectivity for a particular movement direction (Kurata and Wise, 1988).

\section{Precentral cortex}

We found specific preparatory activity in the dorsal aspects of the left precentral gyrus (Table 2, Fig. 3J), confirming that while posterior parietal cortex appears to intervene in the visuomotor transformation regardless of movement performance, some pre- central clusters modulate their DP activity according to the probability of executing a movement (Kalaska and Crammond, 1995). This result might apparently fit into hierarchical schemes of visuomotor processing, with frontal regions closer than parietal areas to movement execution. In fact, parietofrontal connectivity follows a parallel architecture (Caminiti et al., 1998), reflected in the anatomical heterogeneity of the precentral gyrus (Geyer et al., 2000), recently structured along rostral fronto-dependent regions and caudal parieto-dependent regions (Matelli and Luppino, 2001; Picard and Strick, 2001). Accordingly, caudal (but not rostral) precentral responses resembled parietal activity, i.e., they were uncorrelated with subsequent motor responses (Table 3). Finally, left precentral and parietal regions were also similarly involved in movement inhibition, showing stronger activity during $\mathrm{DP}_{\text {Nogo }}$ than during $\mathrm{DP}_{\mathrm{Go}}$, together with a transient $\mathrm{TC}$ related response during Go-Nogo trials (Fig. 3I). Following Strafella and Paus (2001), here we have confirmed that it is possible to spatially segregate neuronal clusters involved in mediating suppression and facilitation of neuromuscular responses.

\section{Prefrontal cortex}

This region displayed significant activity during the DP of both Go and Nogo trials (Tables 2, 3). Such DP responses are unlikely to be related to encoding the sensory material, because hemodynamic signals time-locked to IC were either absent (Fig. $3 L$ ) or limited to the $\mathrm{IC}_{\mathrm{Go}}$ stimuli (Fig. $3 N$ ). Similarly, the pattern of responses time-locked to TC (Fig. $3 L-N$ ) does not appear to be consistent with retrieval phenomena as seen during working memory tasks (Henson et al., 1999; Cadoret et al., 2001). Rather, the negative BOLD response time-locked to $\mathrm{TC}_{\mathrm{Go}-\mathrm{Nogo}}$ (Fig. $3 \mathrm{~L}$, black curve) might reflect the involvement of these prefrontal clusters in tonic inhibitory control, necessary to counterbalance the preparatory drive expressed by other portions of the network (Shallice et al., 1989). During Go-Nogo trials, such an inhibitory mechanism would need to be released, giving rise to negative hemodynamic response. In this perspective, the differential DP activities found in prefrontal cortex (Fig. 3M) might reflect the prediction of particular task contingencies on the basis of the current sensorimotor context (Fuster, 1997), rather than being directly related to preparation of a specific motor response.

\section{Temporal cortex}

We commented on the characteristics of delay-related activity along the superior temporal sulcus in previous related reports (Thoenissen and Toni, 2000; Toni et al., 2001a,b). Here we focus on the delay-related activities found during $\mathrm{DP}_{\mathrm{Go}}$ and $\mathrm{DP}_{\text {Nogo }}$ trials along the medial temporal lobe (Tables 2, 3, Fig. $3 C$ ). These activities spanned both axes of the hippocampal complex (Fig. $3 G)$. A similar distribution of nonspatial delay-related activity has been found in the macaque hippocampus (Colombo et al., 1998), confirming its role in movement-related functions (Halgren, 1991). Recent studies have highlighted the role of the hippocampal complex in establishing arbitrary associations (Henke et al., 1999; Wise and Murray, 1999; Toni et al., 2001a). The delayrelated responses found in this region might represent activity orchestrating the neocortical circuit involved in the associative aspects of the task (Buzsaki, 1996; Rolls, 1996), occurring independently from external input/output (i.e., the sensorimotor items). However, the negative BOLD signals time-locked to the TC during Nogo-Go trials (Fig. 3A, B, magenta curves) indicate that this region is also responsive to transient events, but apparently only when a motor response becomes necessary via a breach in the predominant rule. 


\section{Subcortical structures}

We found specific preparatory activity in several subcortical structures, including the putamen and cerebellum (Fig. $3 C-G$ ). In agreement with Cui et al. (2000), we found that the anterior cerebellum showed only movement-related activity (lobule V) (Fig. 3C, white cluster, D, gray and magenta curves). Conversely, the posterior cerebellum showed both preparatory and movement-related activities (lobule VI) (Fig. 3C, green cluster, E, green and gray curves).

\section{Conclusions}

In this study we have assessed the functional anatomy of motor cognitive processes underlying the flexion of a finger specified by a visual pattern and in response to an auditory trigger cue. By isolating delay-related activity independent from overt sensory and motor events, we have gained insights into cognitive aspects of human behavior. By means of a prelearned associative visuomotor task, combined with the manipulation of the predictive value of an instruction cue, we have challenged not only the interplay between spatial frames of reference and kinematic control processes, but also the extraction of contextual information from the task contingencies. Our data suggest that posterior parietal cortex and dorsal precentral cortex might play different strategic roles in solving these visuomotor problems. While posterior parietal cortex covers a range of potential responses defined by the task setting, dorsal precentral cortex focuses on a probable movement. We speculate that a distributed temporoprefrontal system gathers information on such potential and probable responses on the basis of the trial-by-trial contingencies. Finally, it might be noticed that prefrontal and temporal regions, although supposedly involved in regulating behavioral responses during task performance (Frith et al., 1991; Fuster, 1997; Hyder et al., 1997), operated independently from overt verbal reports, a sign of awareness of regulation of actions.

\section{REFERENCES}

Andersen RA, Snyder LH, Bradley DC, Xing J (1997) Multimodal representation of space in the posterior parietal cortex and its use in planning movements. Annu Rev Neurosci 20:303-330.

Burnod Y, Baraduc P, Battaglia-Mayer A, Guigon E, Koechlin E, Ferraina S, Lacquaniti F, Caminiti R (1999) Parieto-frontal coding of reaching: an integrated framework. Exp Brain Res 129:325-346.

Buzsaki G (1996) The hippocampo-neocortical dialogue. Cereb Cortex 6:81-92.

Cadoret G, Pike GB, Petrides M (2001) Selective activation of the ventrolateral prefrontal cortex in the human brain during active retrieval processing. Eur J Neurosci 14:1164-1170.

Calton JL, Dickinson AR, Snyder LH (2002) Non-spatial, motor-specific activation in posterior parietal cortex. Nat Neurosci 5:580-588.

Caminiti R, Ferraina S, Mayer AB (1998) Visuomotor transformations: early cortical mechanisms of reaching. Curr Opin Neurobiol 8:753-761.

Chafee MV, Goldman-Rakic PS (1998) Matching patterns of activity in primate prefrontal area $8 \mathrm{a}$ and parietal area 7ip neurons during a spatial working memory task. J Neurophysiol 79:2919-2940.

Cisek P, Kalaska JF (2002) Simultaneous encoding of multiple potential reach directions in dorsal premotor cortex. J Neurophysiol 87:1149-1154.

Colby CL, Goldberg ME (1999) Space and attention in parietal cortex. Annu Rev Neurosci 22:319-349.

Colombo M, Fernandez T, Nakamura K, Gross CG (1998) Functional differentiation along the anterior-posterior axis of the hippocampus in monkeys. J Neurophysiol 80:1002-1005.

Crammond DJ, Kalaska JF (2000) Prior information in motor and premotor cortex: activity during the delay period and effect on premovement activity. J Neurophysiol 84:986-1005.

Cui SZ, Li EZ, Zang YF, Weng XC, Ivry R, Wang JJ (2000) Both sides of human cerebellum involved in preparation and execution of sequential movements. NeuroReport 11:3849-3853.

Duhamel JR, Colby CL, Goldberg ME (1992) The updating of the representation of visual space in parietal cortex by intended eye movements. Science 255:90-92.

Duvernoy HM, Cabanis EA, Vannson JL (1991) The human brain: surface, three-dimensional sectional anatomy and MRI. Vienna: Springer.

Eskandar EN, Assad JA (1999) Dissociation of visual, motor and predictive signals in parietal cortex during visual guidance. Nat Neurosci 2:88-93.

Friston KJ, Holmes AP, Poline JB, Grasby PJ, Williams SC, Frackowiak RS, Turner R (1995a) Analysis of fMRI time-series revisited. NeuroImage $2: 45-53$.

Friston KJ, Holmes AP, Worsley KJ, Poline JB, Frith C, Frackowiak RS (1995b) Statistical parametric maps in functional imaging: a general linear approach. Hum Brain Mapp 2:189-210.

Friston KJ, Price CJ, Fletcher P, Moore C, Frackowiak RS, Dolan RJ (1996) The trouble with cognitive subtraction. NeuroImage 4:97-104.

Friston KJ, Josephs O, Rees G, Turner R (1998) Nonlinear eventrelated responses in fMRI. Magn Reson Med 39:41-52.

Friston KJ, Holmes AP, Worsley KJ (1999a) How many subjects constitute a study? NeuroImage 10:1-5.

Friston KJ, Holmes AP, Price CJ, Buchel C, Worsley KJ (1999b) Multisubject fMRI studies and conjunction analyses. NeuroImage 10:385-396.

Frith CD (2000) The role of dorsolateral prefrontal cortex in the selection of action. In: Control of cognitive processes: attention and performance X V III (Moody SL, Driver J, eds), pp 122-130. Cambridge, MA: MIT

Frith CD, Friston K, Liddle PF, Frackowiak RS (1991) Willed action and the prefrontal cortex in man: a study with PET. Proc R Soc Lond B Biol Sci 244:241-246.

Fuster JM (1997) The prefrontal cortex: anatomy, physiology, and neuropsychology of the frontal lobe. New York: Lippincott-Raven.

Garavan H, Ross TJ, Stein EA (1999) Right hemispheric dominance of inhibitory control: an event-related functional MRI study. Proc Natl Acad Sci USA 96:8301-8306.

Geyer S, Matelli M, Luppino G, Zilles K (2000) Functional neuroanatomy of the primate isocortical motor system. Anat Embryol (Berl) 202:443-474.

Gilbert C, Ito M, Kapadia M, Westheimer G (2000) Interactions between attention, context and learning in primary visual cortex. Vision Res 40:1217-1226.

Gitelman DR, Parrish TB, LaBar KS, Mesulam MM (2000) Real-time monitoring of eye movements using infrared video-oculography during functional magnetic resonance imaging of the frontal eye fields. NeuroImage 11:58-65.

Goodale MA, Milner AD, Jakobson LS, Carey DP (1991) A neurological dissociation between perceiving objects and grasping them. Nature 349:154-156.

Gottlieb JP, Kusunoki M, Goldberg ME (1998) The representation of visual salience in monkey parietal cortex. Nature 391:481-484.

Halgren E (1991) Firing of human hippocampal units in relation to voluntary movements. Hippocampus 1:153-161.

Henke K, Weber B, Kneifel S, Wieser HG, Buck A (1999) Human hippocampus associates information in memory. Proc Natl Acad Sci USA 96:5884-5889.

Henson RN, Shallice T, Dolan RJ (1999) Right prefrontal cortex and episodic memory retrieval: a functional MRI test of the monitoring hypothesis. Brain 122:1367-1381.

Hyder F, Phelps EA, Wiggins CJ, LaBar KS, Blamire AM, Shulman RG (1997) "Willed action": a functional MRI study of the human prefrontal cortex during a sensorimotor task. Proc Natl Acad Sci USA 94:6989-6994

Ilan AB, Miller J (1998) On the temporal relations between memory scanning and response preparation. J Exp Psychol Hum Percept Perform 24:1501-1520.

Jeannerod M (1997) The cognitive neuroscience of action. Oxford: Blackwell.

Josephs O, Turner R, Friston KJ (1997) Event-related fMRI. Hum Brain Mapp 5:243-248.

Kalaska JF, Crammond DJ (1995) Deciding not to GO: neuronal correlates of response selection in a $\mathrm{GO} / \mathrm{NOGO}$ task in primate premotor and parietal cortex. Cereb Cortex 5:410-428.

Kastner S, Pinsk MA, De Weerd P, Desimone R, Ungerleider LG (1999) Increased activity in human visual cortex during directed attention in the absence of visual stimulation. Neuron 22:751-761.

Kurata K, Wise SP (1988) Premotor cortex of rhesus monkeys: setrelated activity during two conditional motor tasks. Exp Brain Res 69:327-343.

Kusunoki M, Gottlieb J, Goldberg ME (2000) The lateral intraparietal area as a salience map: the representation of abrupt onset, stimulus motion, and task relevance. Vision Res 40:1459-1468.

Low KA, Miller J (1999) The usefulness of partial information: effects of go probability in the choice/Nogo task. Psychophysiology 36:288-297.

Lynch JC (1980) The functional organization of posterior parietal association cortex. Behav Brain Sci 3:485-534.

Macaluso E, Frith CD, Driver J (2002) Directing attention to locations and to sensory modalities: multiple levels of selective processing revealed with PET. Cereb Cortex 12:357-368. 
Matelli M, Luppino G (2001) Parietofrontal circuits for action and space perception in the macaque monkey. NeuroImage 14:S27-S32.

Miller JO, Low K (2001) Motor processes in simple, go/no-go, and choice reaction time tasks: a psychophysiological analysis. J Exp Psychol Hum Percept Perform 27:266-289.

Mishkin M, Ungerleider LG, Macko KA (1983) Object vision and spatial vision: two cortical pathways. Trends Neurosci 6:414-417.

Mountcastle VB, Lynch JC, Georgopoulos A, Sakata H, Acuna C (1975) Posterior parietal association cortex of the monkey: command functions for operations within extrapersonal space. J Neurophysiol 38:871-908.

Oldfield RC (1971) The assessment and analysis of handedness: the Edinburgh inventory. Neuropsychologia 9:97-113.

Ono M, Kubik S, Abernathey CD (1990) Atlas of the cerebral sulci. New York: Thieme Verlag.

Passingham RE, Toni I, Rushworth MF (2000) Specialisation within the prefrontal cortex: the ventral prefrontal cortex and associative learning. Exp Brain Res 133:103-113.

Picard N, Strick PL (2001) Imaging the premotor areas. Curr Opin Neurobiol 11:663-672.

Platt ML, Glimcher PW (1999) Neural correlates of decision variables in parietal cortex. Nature 400:233-238.

Quintana J, Fuster JM (1999) From perception to action: temporal integrative functions of prefrontal and parietal neurons. Cereb Cortex 9:213-221.

Robinson DL, Goldberg ME, Stanton GB (1978) Parietal association cortex in the primate: sensory mechanisms and behavioral modulations. J Neurophysiol 41:910-932.

Rolls ET (1996) A theory of hippocampal function in memory. Hippocampus 6:601-620.

Rossetti Y, Pisella L (2002) Mediate responses as direct evidence for intention: neuropsychology of Not to-, Not now- and Not there- tasks. In: Cognitive neuroscience perspectives on the problem of intentional action (Johnson S, ed), pp 201-210. Cambridge, MA: MIT.

Rowe JB, Toni I, Josephs O, Frackowiak RS, Passingham RE (2000) The prefrontal cortex: response selection or maintenance within working memory? Science 288:1656-1660.

Schmahmann JD, Doyon J, McDonald D, Holmes C, Lavoie K, Hurwitz
AS, Kabani N, Toga A, Evans A, Petrides M (1999) Threedimensional MRI atlas of the human cerebellum in proportional stereotaxic space. NeuroImage 10:233-260.

Shallice T, Burgess PW, Schon F, Baxter DM (1989) The origins of utilization behaviour. Brain 112:1587-1598.

Snyder LH (2000) Coordinate transformations for eye and arm movements in the brain. Curr Opin Neurobiol 10:747-754.

Snyder LH, Batista AP, Andersen RA (1997) Coding of intention in the posterior parietal cortex. Nature 386:167-170.

Snyder LH, Batista AP, Andersen RA (2000) Intention-related activity in the posterior parietal cortex: a review. Vision Res 40:1433-1441.

Strafella AP, Paus T (2001) Cerebral blood-flow changes induced by paired-pulse transcranial magnetic stimulation of the primary motor cortex. J Neurophysiol 85:2624-2629.

Thoenissen D, Toni I (2000) Movement preparation and motor intention: an event-related fMRI study. Soc Neurosc Abstr 1:178.

Toni I, Krams M, Turner R, Passingham RE (1998) The time course of changes during motor sequence learning: a whole-brain fMRI study. NeuroImage 8:50-61.

Toni I, Schluter ND, Josephs O, Friston K, Passingham RE (1999) Signal-, set- and movement-related activity in the human brain: an event-related fMRI study Cereb Cortex [Erratum (1999) 9:196] 9:35-49.

Toni I, Ramnani N, Josephs O, Ashburner J, Passingham RE (2001a) Learning arbitrary visuomotor associations: temporal dynamic of brain activity. NeuroImage 14:1048-1057.

Toni I, Thoenissen D, Zilles K (2001b) Movement preparation and motor intention. NeuroImage 14:S110-S117.

Toni I, Shah NJ, Fink GR, Thoenissen D, Passingham RE, Zilles K (2002a) Multiple movement representations in the human brain: an event-related fMRI study. J Cognit Neurosci 14:769-784.

Toni I, Thoenissen D, Zilles K, Niedeggen M (2002b) Movement preparation and working memory: a behavioural dissociation. Exp Brain Res 142:158-162.

Wise SP, Murray EA (1999) Role of the hippocampal system in conditional motor learning: mapping antecedents to action. Hippocampus 9:101-117. 